\title{
IDH2 gene deficiency accelerates unilateral ureteral obstruction- induced kidney inflammation through oxidative stress and activation of macrophages
}

\author{
Jee In Kim', Mi Ra Noh², Ga-Eun Yoon ${ }^{1}$, Hee-Seong Jang ${ }^{2}$, Min Jung Kong ${ }^{2}$, and Kwon Moo Park ${ }^{2 * *}$ \\ 'Department of Molecular Medicine and Medical Research Center, Keimyung University School of Medicine, Daegu 42601, ${ }^{2}$ Department of Anatomy and BK21 \\ Plus, School of Medicine, Kyungpook National University, Daegu 41944, Korea
}

\section{ARTICLE INFO}

Received August 27, 2020

Revised November 17, 2020

Accepted December 11, 2020

*Correspondence

Kwon Moo Park

E-mail:kmpark@knu.ac.kr

Key Words

$\mathrm{IDH} 2$

Inflammation

Macrophage

Oxidative stress

Ureteral obstruction
ABSTRACT Mitochondrial NADP ${ }^{+}$-dependent isocitrate dehydrogenase 2 (IDH2) produces NADPH, which is known to inhibit mitochondrial oxidative stress. Ureteral obstruction induces kidney inflammation and fibrosis via oxidative stress. Here, we investigated the role and underlying mechanism of IDH2 in unilateral ureteral obstruction (UUO)-induced kidney inflammation using IDH2 gene deleted mice $\left(I D H 2^{-/-}\right)$. Eight- to 10 -week-old female $I D H 2^{-/-}$mice and wild type $\left(I D H 2^{+/+}\right)$littermates were subjected to UUO and kidneys were harvested 5 days after UUO. IDH2 was not detected in the kidneys of $I D H 2^{-/-}$mice, while UUO decreased IDH2 in IDH2 ${ }^{+/+}$mice. UUO increased the expressions of markers of oxidative stress in both $\mathrm{IDH} 2^{+/+}$and $I D H 2^{-/-}$mice, and these changes were greater in $I D H 2^{-/-}$mice compared to $I D H 2^{+/+}$ mice. Bone marrow-derived macrophages of $\mathrm{IDH} 2^{-/-}$mice showed a more migrating phenotype with greater ruffle formation and Rac1 distribution than that of $I D H 2^{+/+}$ mice. Correspondently, UUO-induced infiltration of monocytes/macrophages was greater in $I D H 2^{-/-}$mice compared to IDH2 $2^{+/+}$mice. Taken together, these data demonstrate that IDH2 plays a protective role against UUO-induced inflammation through inhibition of oxidative stress and macrophage infiltration.

\section{INTRODUCTION}

Ureteral obstruction (UO) that leads to tubular atrophy, interstitial inflammation, and fibrosis is a common cause of renal impairment in children and adults [1,2]. The unilateral ureteral obstruction (UUO) model is the most widely used rodent experimental model of the pathophysiology of acute kidney inflammation and chronic renal fibrosis induced by human UO [3]. UUO induces tubular cell death, interstitial inflammatory cell infiltration, capillary rarefaction, and progressive fibrosis with loss of renal parenchyma. UUO-induced inflammation and consequent fibrosis are strongly related to oxidative stress caused by the overproduction of reactive oxygen species (ROS) or downregulation of ROS scavengers [4].
There are various ROS scavengers, including superoxide dismutases, catalases, glutathione peroxidases, and thiol-containing enzymes such as thioredoxins, thioredoxin reductases, peroxiredoxins, and glutaredoxins [5-7]. $\mathrm{NAD}(\mathrm{P}) \mathrm{H}$ plays a critical role in the antioxidant system as a required factor for these antioxidant enzymes [6]. Isocitrate dehydrogenases (IDHs) produce $\mathrm{NAD}(\mathrm{P})$ $\mathrm{H}$ by reduction of $\mathrm{NAD}(\mathrm{P})$ during oxidative decarboxylation of isocitrate to $\alpha$-ketoglutarate [8]. Among the 3 isotypes of mammal IDHs (IDH1, IDH2, and IDH3), IDH2 is an NADP ${ }^{+}$-dependent NADPH-producing anti-oxidative enzyme effective against cell dysfunction and cell death and aging such as hair grayness, skin pathology, and renal dysfunction [9]. Accordingly, we have previously reported that IDH2 plays a protective role in various pathologic conditions such as kidney ischemia/reperfusion (I/

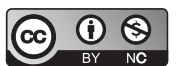

This is an Open Access article distributed under the terms of the Creative Commons Attribution Non-Commercial License, which permits unrestricted non-commercial use, distribution, and reproduction in any medium, provided the original work is properly cited. Copyright @ Korean J Physiol Pharmacol, pISSN 1226-4512, elSSN 2093-3827
Author contributions: J.I.K. conceived and designed research. J.I.K., M.R.N., G.E.Y., H.S.J., and M.J.K. conducted experiments. J.I.K. and K.M.P. analyzed and interpreted data. J.I.K. prepared the draft. J.I.K. and K.M.P. edited the manuscript. All authors read and approved the manuscript. 
R) injury [10], liver I/R injury [11], and cisplatin-induced kidney injury through the defense of tissues against oxidative stress [12]. Even though UUO-induced renal injury critically depends on the oxidative stress [4], the role of IDH2 in UUO-induced renal inflammation and the underlying mechanism is largely unknown.

Cells of monocyte/macrophage lineage are often the predominant infiltrating cell types in both experimental models and human renal diseases, and there is a close correlation between the renal infiltration of macrophages and oxidative stress [4,13]. Furthermore, the phenotypes and quantity of infiltrating macrophages are important factors affecting inflammation and fibrosis after UUO [14,15]. Therefore, knowledge of infiltrative macrophages and modulating characteristics of macrophages may yield novel approaches in treating UUO-induced renal inflammation and fibrosis [15]. Here, we investigated the role of IDH2 in UUOinduced oxidative stress, macrophage phenotype change, and infiltration into the kidney, renal inflammation, and the underlying mechanism of action in this setting.

\section{METHODS}

\section{Animal experiments}

All animal experiments were conducted in accordance with the guidelines provided by the Animal Care and Use Committee of Kyungpook National University. The experimental protocol (KNU 2014-0058) was approved by the Institutional Animal Care and Use Committee at Kyungpook National University. Eightto 10 -week-old female $\mathrm{IDH} 2$ gene-deleted $\left(\mathrm{IDH} 2^{-/}\right)$mice and wild type $\left(I D H 2^{+/ t}\right)$ littermates were used in the experiments. Pan et al. [16] reported that $I D H 2^{-/}$females are more susceptible to fructose-induced non-alcoholic fatty liver disease and the associated inflammatory response. Therefore, we used female mice because UUO-induced damage largely depends on inflammatory responses. Generation and characterization of $\mathrm{IDH}^{-/}$mice have been described previously [17]. Mice were allowed free access to water and standard chow. Mice were anesthetized by intraperitoneal injection of pentobarbital sodium $(50 \mathrm{mg} / \mathrm{kg}$ body weight; Sigma-Aldrich Corp., St. Louis, MO, USA) before surgery. For UUO surgery, the right kidney was exposed via a flank incision, the right ureter was completely obstructed near the renal pelvis by $6-0$ nylon, and the incision was subsequently sutured. Sham operations were conducted according to the same surgical procedure except for the ureter ligation. Kidneys were harvested 5 days after UUO and were either snap-frozen in liquid nitrogen for biochemical analysis or perfusion-fixed in PLP (4\% paraformaldehyde, $75 \mathrm{mM}$ L-lysine, and $10 \mathrm{mM}$ sodium periodate; SigmaAldrich Corp.) for histological studies [18].

\section{Western blot analysis}

Protein samples were prepared by lysis of kidneys or cells with lysis buffer containing $20 \mathrm{mM}$ Tris- $\mathrm{HCl}$ ( $\mathrm{pH}$ 7.5), $150 \mathrm{mM} \mathrm{NaCl}, 1$ mM Na 2 EDTA, 1 mM EGTA, 1\% NP-40, 1\% sodium deoxycholate, $2.5 \mathrm{mM}$ sodium pyrophosphate, $1 \mathrm{mM} \beta$-glycerophosphate, $1 \mathrm{mM} \mathrm{Na}_{3} \mathrm{VO}_{4}, 1 \mu \mathrm{g} / \mathrm{ml}$ leupeptin, $50 \mu \mathrm{M}$ PMSF, $10 \mu \mathrm{M}$ pepstatin A, $100 \mu \mathrm{M}$ benzamidine, and $50 \mu \mathrm{M}$ bestatin. The lysate was centrifuged at $15,000 \mathrm{rpm}$ at $4^{\circ} \mathrm{C}$. The supernatant was taken and the concentrations of proteins were measured using a BCA kit (Thermo Fisher Scientific, San Diego, CA, USA). Lysates and 5X SDS-PAGE loading buffer (Intron, Seongnam, Korea) were mixed and heated at $98^{\circ} \mathrm{C}$ for $5 \mathrm{~min}$. SDS samples were stored at $-20^{\circ} \mathrm{C}$ until use. Protein samples were electrophoresed on $10 \%$ to $12 \%$ polyacrylamide gel with $0.1 \%$ SDS and transferred to PVDF membranes, and then subjected to immunoblotting with antibodies against IDH2 [19], 4-hydroxynonenal (HNE; Abcam Inc., Cambridge, MA, USA), and lymphocyte antigen 6 complex (Ly6G; eBioscience, San Diego, CA, USA), For loading control, antiglyceraldehyde 3-phosphate dehydrogenase (GAPDH; Novus Biologicals, Littleton, CO, USA) antibody was used. Horseradish peroxidase-conjugated secondary antibodies (anti-rabbit: Santa Cruz, Santa Cruz, CA, USA; anti-mouse: Bethyl, Montgomery, TX, USA) were applied. Immunoblots were visualized using chemiluminescence reagent (PerkinElmer Life Sciences, Waltham, MA, USA). Immunoblot densities were quantified using image analysis software ImageJ (NIH, Bethesda, MD, USA).

\section{Isolation of mitochondria from kidney tissue}

The procedures for the fraction is as follows [20]. Briefly, kidney tissue was homogenized in sucrose buffer $(0.2 \mathrm{M}$ sucrose, $1 \mathrm{mM}$ EGTA, $10 \mathrm{mM}$ HEPES, pH 7.4; Sigma-Aldrich Corp.) using a Teflon homogenizer (Daihan Scientific, Seoul, Korea). The homogenate was centrifuged at $600 \times \mathrm{g}$ for $10 \mathrm{~min}$ at $4^{\circ} \mathrm{C}$. The supernatant was transferred to a new tube and centrifuged at 7,000 $\times \mathrm{g}$ for $10 \mathrm{~min}$. The mitochondrial pellet was washed twice with sucrose buffer and centrifuged at 7,000 $\times \mathrm{g}$ for $10 \mathrm{~min}$. The pellet was suspended with sonication buffer (0.1\% Triton X-100 in PBS) and sonicated twice using a 4710 series sonicator (Cole-Palmer, Chicago, IL, USA) at a $40 \%$ output setting for $10 \mathrm{sec}$. After centrifugation at $15,000 \times \mathrm{g}$ for $30 \mathrm{~min}$, the supernatant containing mitochondria was collected. It was used to measure the mitochondrial hydrogen peroxide levels and oxidative stress.

\section{Measurement of mitochondrial hydrogen peroxide levels in the kidney}

Xylenol orange (Sigma-Aldrich Corp.), a ferric-sensitive dye, was used to measure the hydrogen peroxide levels in the kidney mitochondrial homogenates. This measurement is based on the following principle: $\mathrm{H}_{2} \mathrm{O}_{2}$ oxidizes iron (II) to iron (III) in the 
presence of sorbitol, which acts as a catalyst. Iron (III) makes a purple complex with xylenol orange. The procedure is as follows. $100 \mu \mathrm{g}$ kidney mitochondrial homogenates were incubated with $900 \mu \mathrm{l}$ Fox reagent containing $0.25 \mathrm{M} \mathrm{H}_{2} \mathrm{SO}_{4}, 1 \mathrm{M}$ sorbitol, 25 $\mathrm{mM}$ ferrous ammonium sulfate, $1 \mathrm{mM}$ xylenol orange at room temperature for $30 \mathrm{~min}$. Then, the absorbance was read at 560 $\mathrm{nm}$ using a microplate reader (GEMINI EM, Molecular Devices, Sunnyvale, CA, USA). Using this value, hydrogen peroxide levels were calculated.

\section{Immunohistochemistry staining}

PLP-fixed kidneys were washed with PBS three times for $5 \mathrm{~min}$ each time, embedded in paraffin, and $3 \mu \mathrm{m}$ thick-sectioned using a microtome (RM2165; Leica, Bensheim, Germany). Immunohistochemical staining was performed as described previously using anti-F4/80 antibody (Serotec, Oxford, UK). Briefly, deparaffinization and rehydration were performed by successive immersion for $10 \mathrm{~min}$ in xylene, ethanol $(100 \%, 90 \%, 80 \%$, and $70 \%$; v/v), and distilled water. After a 5 -min permeabilization period with $0.1 \%$ Triton X-100/PBS (w/v) and a $1 \mathrm{~h}$ blocking with 3\% BSA/PBS (w/ v), the sections were incubated with primary antibody overnight at $4^{\circ} \mathrm{C}$. The sections were washed three times in PBS for $5 \mathrm{~min}$ each, incubated with HRP-conjugated secondary antibody (antirat IgG; Bethyl Laboratories). Then sections were incubated with DAB substrate (Vector Laboratories, Inc., Burlingame, CA, USA). Hematoxylin and eosin (H\&E) staining (Muto Pure Chemicals, Tokyo, Japan) was used to visualize nuclei. Images were captured using a Leica DM2500 microscope (Leica instruments, Wezlar, Germany). F4/80-positive cells were counted in 10 fields $\left(\mathrm{mm}^{2}\right.$ per field) per kidney.

\section{Bone marrow-derived macrophage preparation}

Bone marrow was collected from femurs and tibias by flushing with DMEM (Corning, Corning, NY, USA). The collection was filtered through a $40 \mu \mathrm{m}$ pore cell strainer and then RBCs were lysed using RBC lysis buffer. Cells were washed with PBS and incubated on the culture dish for $4 \mathrm{~h}$ at $37^{\circ} \mathrm{C}$. Supernatants were collected and centrifuged. The pellet was resuspended and then incubated in DMEM supplemented with 10\% FBS (Welgene Inc., Daegu, Korea), $100 \mu \mathrm{g} / \mathrm{ml}$ streptomycin (Welgene Inc.), $100 \mathrm{U} / \mathrm{ml}$ penicillin (1XS/P) (Welgene Inc.), and $20 \%$ conditioned medium of L929 cells, which is a source of macrophage colony-stimulating factor (M-CSF), at $37^{\circ} \mathrm{C}$ for 7 days. Images of macrophages were captured using a Leica DM2500 microscope (Leica instruments, Wezlar, Germany). L929 cell-conditioned medium was obtained from L929 cell culture. L929 cells (ATCC, Manassas, VA, USA) were grown to confluence in DMEM, $10 \% \mathrm{FBS}$, and $1 \mathrm{X} \mathrm{S/P}$ at $37^{\circ} \mathrm{C}$. After 3 days, supernatants were collected and used.

\section{Migration assay}

Migration of bone marrow-derived macrophages was determined as described previously using a Boyden chamber (Corning Costar, Cambridge, MA, USA) that contains a polycarbonate transwell membrane filter $(6.5 \mathrm{~mm}$ diameter, $8 \mu \mathrm{m}$ pore size $)$ with a little modification [21]. $20 \times 10^{4}$ cells were seeded into the insert chamber in DMEM (Corning) with 1\% FBS (Gibco, Grand Island, NY, USA). The lower chamber was filled with DMEM with $10 \%$ FBS. Cells were incubated for $4 \mathrm{~h}$ at $37^{\circ} \mathrm{C}$ in a humidified atmosphere containing $5 \% \mathrm{CO}_{2}$. Cells were migrated through the pores of the membrane at the bottom of the insert chamber. After the remaining cells were scraped from the upper surface of the membrane with a cotton swab, migrated cells on the lower surface of the membrane were stained with hematoxylin and eosin and then counted. Pictures were taken using a microscope (Leica; Leica instruments, Wetzlar, Germany).

\section{Immunofluorescence staining}

Bone marrow-derived macrophages cultured on the coverslips were fixed with $4 \%$ paraformaldehyde for $15 \mathrm{~min}$, permeabilized with $0.1 \%$ Triton-X 100 for $1 \mathrm{~min}$, quenched with $50 \mathrm{mM}$ ammonium chloride for $5 \mathrm{~min}$ and then incubated with 3\% BSA to block non-specific binding. To achieve dual immunofluorescence staining of Racl and IDH2, mouse anti-Racl antibody (BD Biosciences, San Jose, CA, USA) and rabbit anti-IDH2 antibody [22] were mixed and used. The slides were incubated with an antibody mixture overnight at $4^{\circ} \mathrm{C}$. Slides were washed with PBS, and then Cy3-conjugated anti-mouse IgG (Bethyl Laboratories Inc.) and FITC-conjugated anti-rabbit IgG (Bethyl Laboratories Inc.) were applied for $60 \mathrm{~min}$ at room temperature. To detect the cell nuclei, 40-6-diamidino-2-phenylindole (DAPI, \#D9542; Sigma Aldrich) was applied. Finally, the cells were observed and pictures were taken using a fluorescence microscope (Leica; Leica instruments, Wetzlar, Germany).

\section{Statistics}

The results were expressed as the means \pm standard error (SE). Statistical differences between the groups were evaluated with an analysis of variance using a two-tailed Student's t-test. Differences between the groups were considered statistically significant with a p-value of $<0.05$.

\section{RESULTS}

\section{UUO decreased IDH2 expression}

To speculate the role of IDH2 in UUO-induced kidney injury we determined the expression levels of IDH2 following UUO. 
First of all, we confirmed that IDH2 was not expressed in the kidney of $\mathrm{IDH} 2^{-/-}$mice. UUO significantly decreased IDH2 expression ( $\mathrm{p}<0.01$ vs. sham) (Fig. 1A, B).

\section{IDH2 gene deficiency accelerated UUO-induced mitochondrial oxidative stress}

To investigate the role of IDH2 in mitochondrial oxidative stress, we determined the hydrogen peroxide production and the expression of HNE, which is produced by lipid peroxidation, in
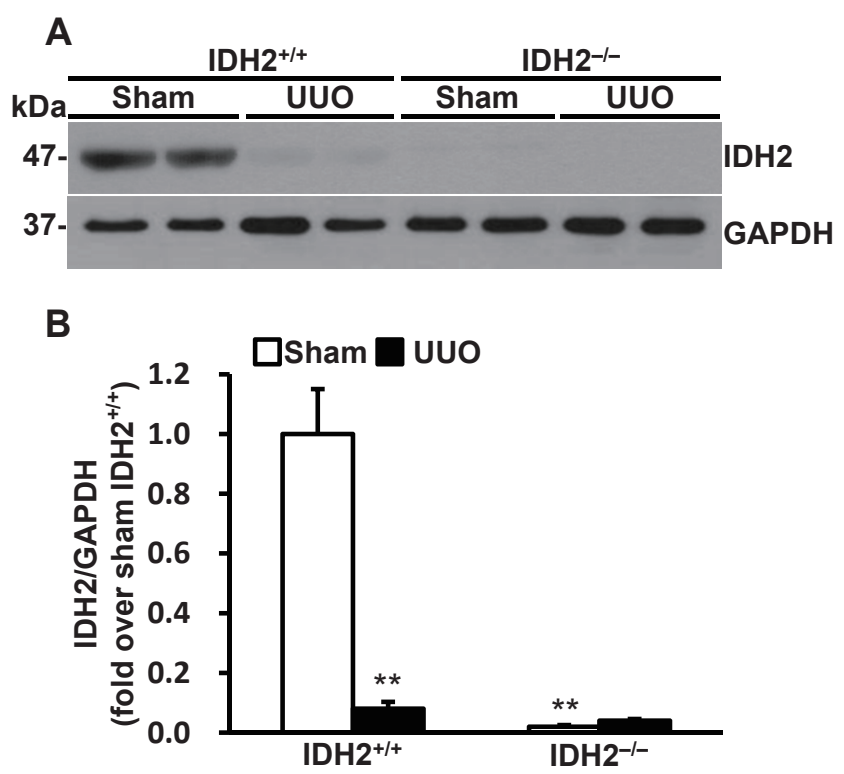

Fig. 1. Unilateral ureteral obstruction (UUO) decreased IDH2 expression. (A, B) IDH2 ${ }^{+/+}$and $I D H 2^{-/-}$female mice were subjected to either UUO or a sham operation. Kidneys were harvested 5 days after the operation. (A) Representative Western blots for IDH2 and GAPDH in the kidneys. (B) The graph summarizes IDH2 expression. Data are presented as mean $\pm \mathrm{SE}(\mathrm{n}=4) .{ }^{* *} \mathrm{p}<0.01$ vs. sham-operated IDH2 ${ }^{+/+}$group. the mitochondrial fraction of the kidney cells. Hydrogen peroxide production in the mitochondria was increased by UUO in both $I D H 2^{+/+}$mice and $I D H 2^{-/-}$mice $(\mathrm{p}<0.01$ vs. their own sham group), while $I D H 2$ gene deficiency accelerated the UUO-induced increase in hydrogen peroxide production $\left(\mathrm{p}<0.01 \mathrm{IDH} 2^{+/+} \mathrm{UUO}\right.$ vs. IDH2 ${ }^{-/}$UUO) (Fig. 2A). HNE level was also increased by UUO in both $I D H 2^{+/+}$mice and $I D H 2^{-/-}$mice ( $p<0.01$ vs. their own sham group), while IDH2 $\mathrm{KO}$ accelerated the UUO-induced increase in HNE ( $\mathrm{p}<0.01 \mathrm{IDH} 2^{+/+} \mathrm{UUO}$ vs. IDH2 ${ }^{-/-} \mathrm{UUO}$ ) (Fig. 2B, C). HNE, 4-hydroxynonenal.

\section{IDH2 gene deficiency accelerated UUO-induced inflammatory cell infiltration into the kidney}

To investigate the role of IDH2 in UUO-induced inflammation, we determined inflammatory cell infiltration in the kidney following UUO. Expression of Ly6G, which is a marker for neutrophils and monocytes, increased in both $\mathrm{IDH}^{+/+}$mice and $I D H 2^{-/-}$mice ( $\mathrm{p}<0.01 \mathrm{vs}$. their own sham group), while $I D H 2$ gene deficiency accelerated increase in Ly6G expression in $I D H 2^{-/-}$mice $\left(\mathrm{p}<0.01 \mathrm{IDH} 2^{+/+} \mathrm{UUO}\right.$ vs. IDH2 $2^{-/-} \mathrm{UUO}$ ) (Fig. $3 \mathrm{~A}, \mathrm{~B})$. Expression of $\mathrm{F} 4 / 80$, which is a macrophage marker, also increased in both $I D H 2^{+/+}$mice and $I D H 2^{-/-}$mice ( $\mathrm{p}<0.01 \mathrm{vs}$. their own sham group), while IDH2 gene deficiency accelerated increase in $\mathrm{F} 4 / 80$ expression in $I D H 2^{-/-}$mice ( $<<0.01 \mathrm{IDH} 2^{+/+}$ UUO vs. IDH2 $2^{--}$UUO) (Fig. 3C, D).

\section{IDH2 gene deficiency accelerated the migration of bone marrow-derived macrophages}

To elucidate the mechanism underlying the increased infiltration of inflammatory cells into the kidney, we investigated the effect of $I D H 2$ gene deficiency on the phenotype change of bone marrow-derived macrophages. First, we observed the morphology of the $\mathrm{IDH} 2^{-/}$mice under the microscope. Ruffle formation of

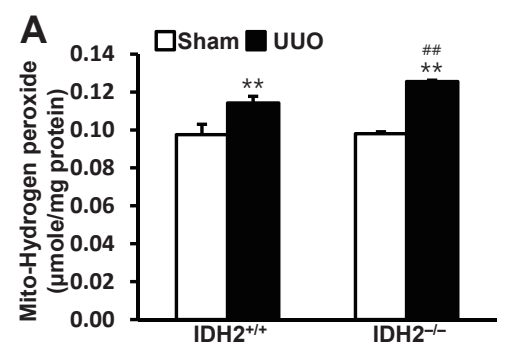

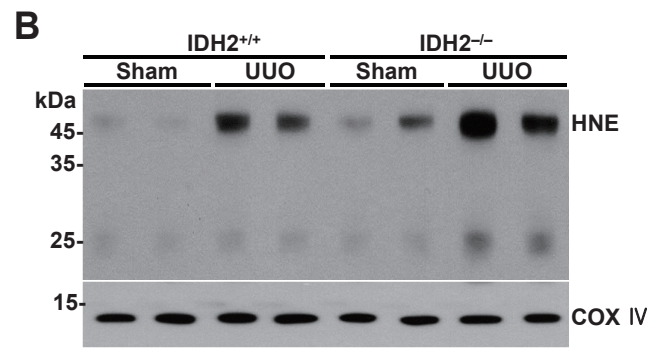

C

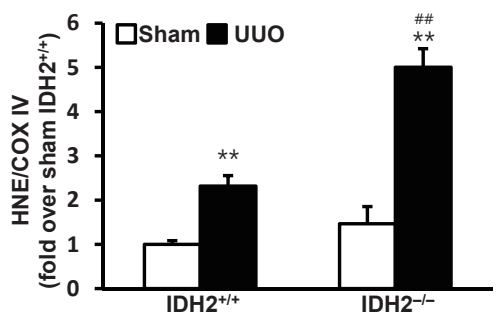

Fig. 2. IDH2 gene deficiency accelerated unilateral ureteral obstruction (UUO)-induced mitochondrial $\mathrm{H}_{2} \mathrm{O}_{2}$ production and lipid peroxidation. $I D H 2^{+/+}$and $I D H 2^{-/-}$female mice were subjected to either UUO or a sham operation. Kidneys were harvested 5 days after the operation. (A) $\mathrm{H}_{2} \mathrm{O}_{2}$ level was measured in the kidney cell mitochondrial fraction. (B) Representative Western blots for HNE and COX IV in the mitochondrial fraction of kidneys. (C) The graph summarizes HNE expression. Data are presented as mean $\pm \mathrm{SE}(\mathrm{n}=3) .{ }^{*} \mathrm{p}<$ 0.01 vs. its own sham-operated group; ${ }^{\# \#}$ $<0.01$ vs. UUO-operated IDH2 ${ }^{+/+}$group. 

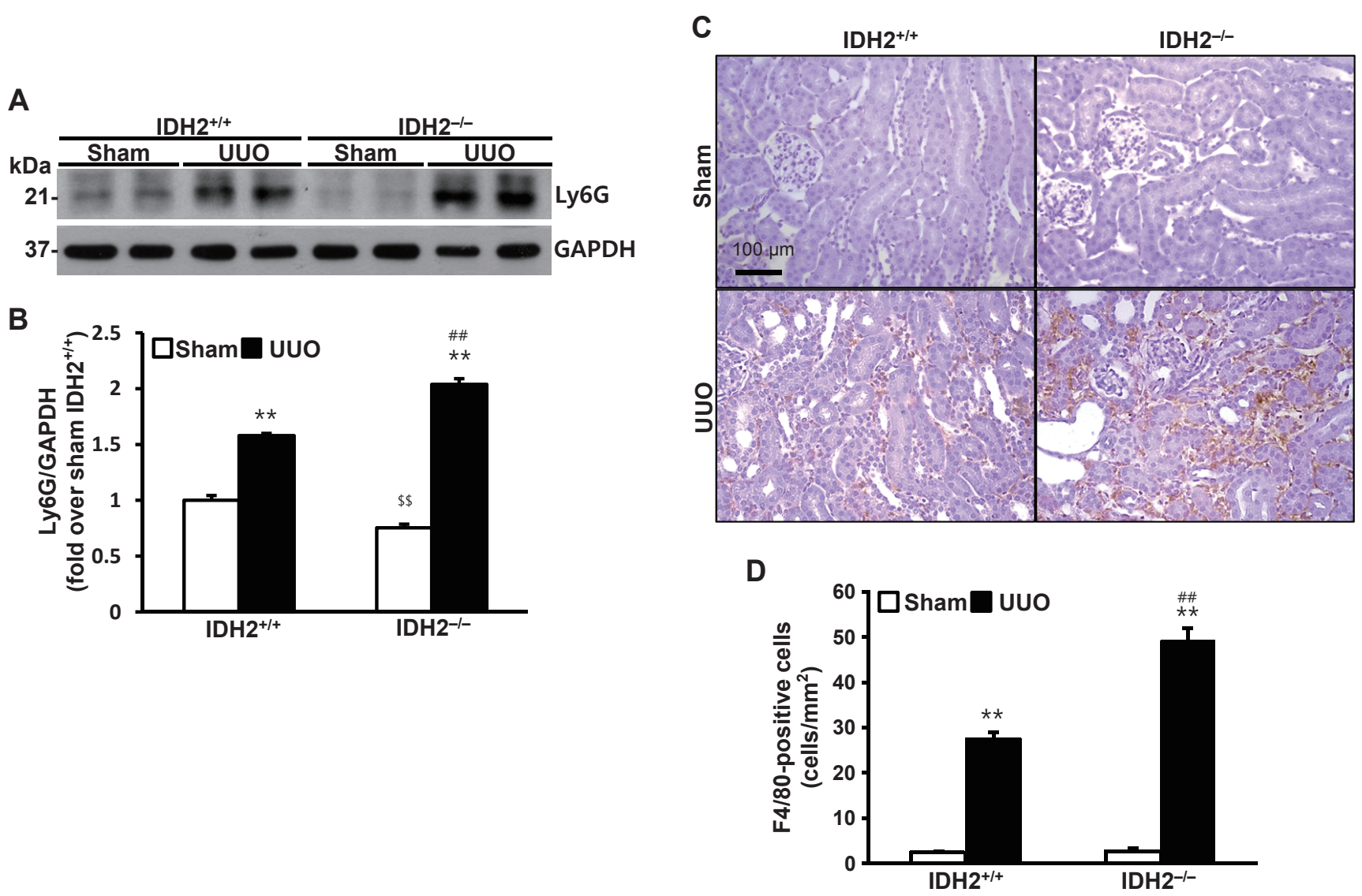

Fig. 3. IDH2 gene deficiency accelerated unilateral ureteral obstruction (UUO)-induced leukocytes infiltration. IDH2 $2^{+/+}$and IDH2 $2^{-/-}$female mice were subjected to either sham or UUO operation. Kidneys were harvested 5 days after the operation. (A) Representative Western blots for Ly6G and GAPDH in the kidneys. (B) The graph summarizes Ly6G expression. ${ }^{*} \mathrm{p}<0.01$ vs. sham-operated own control group. Data are presented as mean $\pm \mathrm{SE}$ $(\mathrm{n}=4) .{ }^{\# \#} \mathrm{p}<0.01$ vs. UUO-operated IDH2 ${ }^{+/+}$group. ${ }^{\$ \$} \mathrm{p}<0.01 \mathrm{vs}$. sham-operated IDH2 ${ }^{+/+}$group. (C) Representative pictures of immunohistochemically stained kidneys against F4/80 (brown). (D) The graph summarizes F4/80 expression. Data are presented as mean \pm SE from 2 independent experiments. ${ }^{* *} \mathrm{p}<0.01$ vs. sham-operated own control group. ${ }^{\# \#} \mathrm{p}<0.01$ vs. UUO-operated IDH2 ${ }^{+/+}$group.

the macrophages was enhanced in $\mathrm{IDH} 2^{-/-}$mice (Fig. 4A). Next, we determined migration using Boyden chamber. The number of migrated macrophages was greater in $\mathrm{IDH}_{2}{ }^{-/-}$mice compared to $I D H 2^{+/+}$mice $\left(\mathrm{p}<0.01 \mathrm{IDH}^{+/ /+}\right.$vs. IDH2 $2^{-/-}$) (Fig. 4B, C). Dual immunofluorescence staining against IDH2 and Rac1 showed enhanced ruffle formation with Racl spread in $\mathrm{IDH}^{-/-}$mice compared to $\mathrm{IDH} 2^{++}$mice (Fig. 4D).

\section{DISCUSSION}

The principal findings of this study are that the NADPH-producing anti-oxidant enzyme IDH2 deficiency increased UUOinduced kidney inflammation through enhanced mitochondrial oxidative stress, phenotype change of macrophages, and infiltration of macrophages into the kidney. UUO also decreased IDH2 expression in $\mathrm{IDH}^{+/+}$mice with oxidative stress and inflammation in the kidney indicating that there is a vicious cycle between kidney injury and a decrease in IDH2 expression.

Ureteral obstruction causes tubular cell injury and death with increased macrophage infiltration, the elevation of proinflammatory cytokines, and proliferation of interstitial fibroblasts resulting in kidney fibrosis, which is a common pathway to the end-stage of renal disease. Findings in the animal models are comparable with observations in patients with obstructive nephropathy [23] suggesting that the rodent model of UUO is useful to study human progressive renal disease offering the beneficial effects of genetic modulation. Oxidative stress contributes importantly to the pathogenesis of UUO. Various markers of oxidative stress, such as 4-HNE are increased in UUO kidneys [24,25]. In accordance with, mice that are genetically deficient in catalase are more susceptible to UUO-induced renal injury [26]. Our group previously revealed the protective role of IDH2 in I/R-induced kidney injury and cisplatin-induced nephrotoxicity using $\mathrm{IDH}^{-{ }^{--}}$ mice. In these studies, we demonstrated the anti-inflammatory role and mechanism of anti-mitochondrial oxidative stress and anti-apoptosis by the IDH2 gene $[10,12]$. However, the role of IDH2 in obstructive kidney disease and the link between IDH2 deficiency and increased inflammation was mostly veiled. Here, we demonstrated that UUO decreased IDH2 and IDH2 defi- 
A

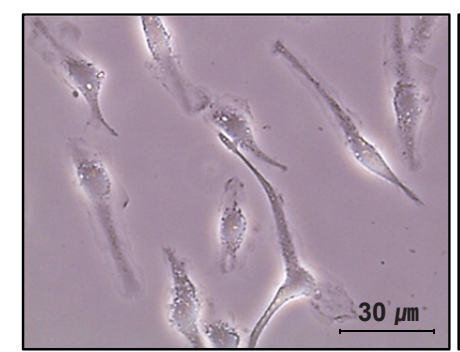

B

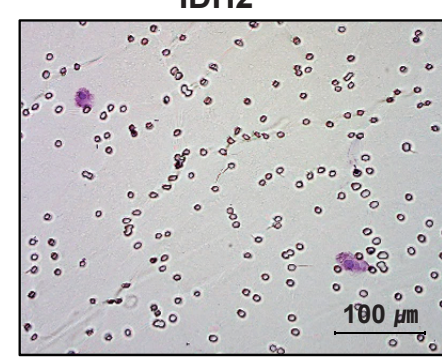

IDH2-1-

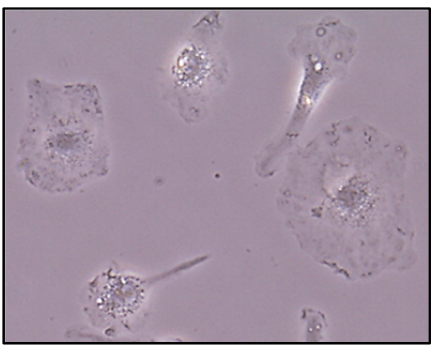

D

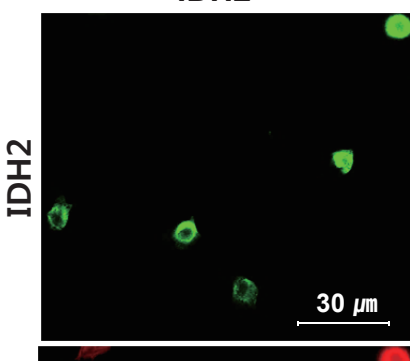

IDH2-I-

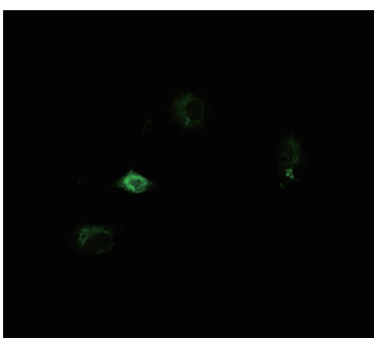

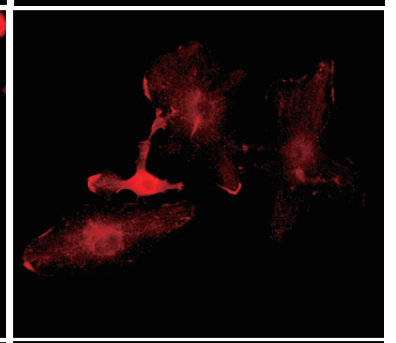
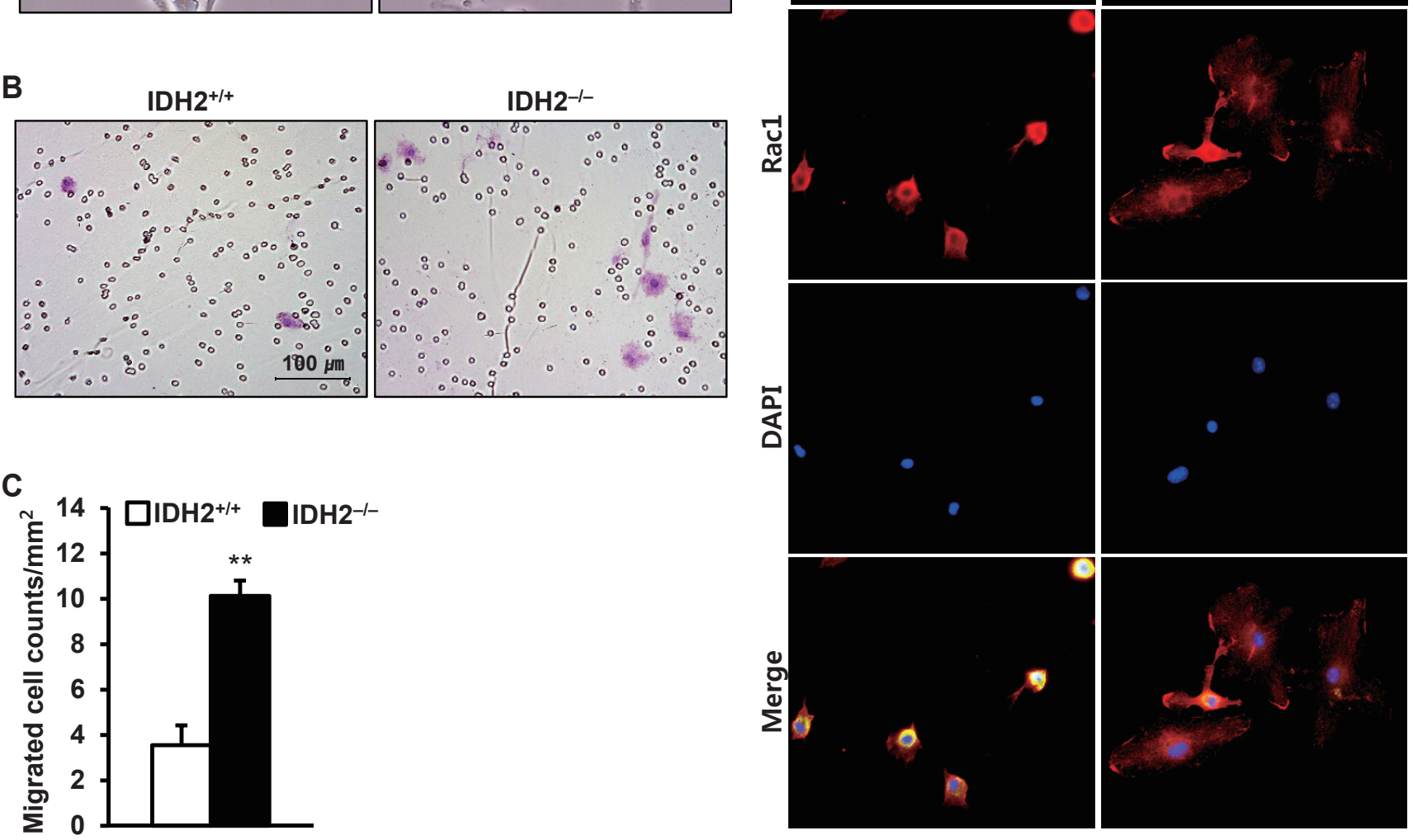

Fig. 4. Migration and ruffle formation of bone marrow-derived macrophages were dependent on the IDH2 expression. (A) Representative pictures of bright field microscopy of cultured bone marrow-derived macrophages of IDH2 $2^{+/+}$and IDH2 $2^{-/-}$mice. (B) Representative pictures of bright field microscopy of H\&E-stained migrated bone marrow-derived macrophages of $I D H 2^{+/+}$and $I D H 2^{-/-}$mice. Macrophages stained pink. Small circles are pores of the membrane filters. (C) The graph summarizes the number of migrated macrophages. Data are presented as mean $\pm S E(n=3)$. ${ }^{* *} p<0.01$ vs. IDH2 ${ }^{+/+}$. (D) Representative images of immunofluorescence staining for IDH2 (green), Rac1 (red), DAPI for nuclear staining (blue), and merge.

ciency aggravated UUO-induced mitochondrial oxidative stress, macrophage activation, and migration resulting in enhanced renal inflammation for the first time.

With the contribution of ROS by other cells, invading immune cells are the major source of oxidative stress during kidney injury. Infiltrating leukocytes (neutrophils and macrophages) release large amounts of inflammatory cytokines and ROS [27]. Macrophage infiltration depends on phenotypes [15]. For example, mice that had received a bone marrow transplant from angiotensin II type 1 receptor null $\left(\mathrm{Agtrl}^{-/}\right)$mice showed reduced macrophage infiltration after UUO [28]. In our study, bone marrow-derived macrophages, which lack IDH2 showed a more migrating phenotype with enhanced ruffle formation and Racl diffusion in the cytosol. IDH2 gene-deficient macrophages migrated more than wild type macrophages. Accordingly, IDH2 gene deficiency increased macrophage infiltration into the kidney after UUO, increasing renal inflammation. Because infiltrating macrophages are major contributors for kidney inflammation [27] and global knockout of IDH2 in this study showed migrating phenotype and increased migration of macrophages, it is suggested that macrophage-selective IDH2 deficiency will give similar results with this study.

It can be expected that the basal ROS level is increased with IDH2 deficiency. However, we could not observe an increased basal ROS level without UUO. It seems that the increase in basal ROS with IDH2 deficiency is minimal. Besides, even UUOinduced increase in hydrogen peroxide level was just $14 \%$ in wild type, which suggests that the increase may be undetectable in this 
system. Nevertheless, it is clear that UUO-induced ROS production and consequent oxidative stress is exaggerated by IDH2 deficiency.

In vitro study of macrophage culture (Fig. 4) showed a more migrating phenotype of IDH2 deficient macrophages without any stimulation but macrophage colony-stimulating factor. Morphology and migration of cells largely depend on cytoskeleton particularly polymerized actin. The effect of ROS on actin polymerization is controversial. Reduction of ROS by free radical scavenger reduced F-actin contents resulting in disassembly of the actin cytoskeleton and reduced neuronal growth cone formation [29]. On the other hand, the NADPH-dependent physiological level of ROS attenuated actin polymerization via actin glutathionylation in the neutrophils [30]. Moreover, mitochondrial ROS levels of $\mathrm{IDH} 2^{+/+}$and $\mathrm{IDH} 2^{-/-}$mice macrophages in this study were not significantly different. Therefore, it is not likely that ROS is responsible for the differences between morphology and migration activities of $\mathrm{IDH}_{2}{ }^{+/+}$and $\mathrm{IDH} 2^{-/}$mice macrophages. We suggest that the differences occur in response to macrophage colonystimulating factor during macrophage differentiation.

Collectively, our results demonstrate that UUO decreases $\mathrm{IDH} 2$ in the kidney, and deficiency of the $\mathrm{IDH} 2$ gene increases obstruction-induced oxidative stress to increase inflammation, at least in part, via activation of macrophages. The present study demonstrates the importance of the presence of IDH2 to inhibit UUO-induced oxidative stress and inflammation in the kidney, offering IDH2 as a novel therapeutic target for obstructive renal injury and macrophage activation.

\section{ACKNOWLEDGEMENTS}

This work was supported by the National Research Foundation of Korea (NRF) Grant (MSIP No. 2014R1A5A2010008 and NRF2020R1A2C2008039 to JI Kim) funded by the Korean government and grant of the Korea Health Technology R\&D Project (No. HI15C0001 to KM Park) through the Korea Health Industry Development Institute (KHIDI), funded by the Ministry of Health \& Welfare, Republic of Korea.

\section{CONFLICTS OF INTEREST}

The authors declare no conflicts of interest.

\section{REFERENCES}

1. Sacks SH, Aparicio SA, Bevan A, Oliver DO, Will EJ, Davison AM. Late renal failure due to prostatic outflow obstruction: a preventable disease. BMJ. 1989;298:156-159.

2. Chevalier RL, Thornhill BA, Forbes MS, Kiley SC. Mechanisms of renal injury and progression of renal disease in congenital obstructive nephropathy. Pediatr Nephrol. 2010;25:687-697.

3. Ucero AC, Benito-Martin A, Izquierdo MC, Sanchez-Niño MD, Sanz AB, Ramos AM, Berzal S, Ruiz-Ortega M, Egido J, Ortiz A. Unilateral ureteral obstruction: beyond obstruction. Int Urol Nephrol. 2014;46:765-776.

4. Dendooven A, Ishola DA Jr, Nguyen TQ, Van der Giezen DM, Kok RJ, Goldschmeding R, Joles JA. Oxidative stress in obstructive nephropathy. Int J Exp Pathol. 2011;92:202-210.

5. Marí M, Morales A, Colell A, García-Ruiz C, Fernández-Checa JC. Mitochondrial glutathione, a key survival antioxidant. Antioxid Redox Signal. 2009;11:2685-2700.

6. Birben E, Sahiner UM, Sackesen C, Erzurum S, Kalayci O. Oxidative stress and antioxidant defense. World Allergy Organ J. 2012;5:919.

7. Harris IS, Treloar AE, Inoue S, Sasaki M, Gorrini C, Lee KC, Yung KY, Brenner D, Knobbe-Thomsen CB, Cox MA, Elia A, Berger T, Cescon DW, Adeoye A, Brüstle A, Molyneux SD, Mason JM, Li WY, Yamamoto K, Wakeham A, et al. Glutathione and thioredoxin antioxidant pathways synergize to drive cancer initiation and progression. Cancer Cell. 2015;27:211-222.

8. Reitman ZJ, Yan H. Isocitrate dehydrogenase 1 and 2 mutations in cancer: alterations at a crossroads of cellular metabolism. J Natl Cancer Inst. 2010;102:932-941.

9. Lee SJ, Cha H, Lee S, Kim H, Ku HJ, Kim SH, Park JH, Lee JH, Park KM, Park JW. Idh2 deficiency accelerates renal dysfunction in aged mice. Biochem Biophys Res Commun. 2017;493:34-39.

10. Han SJ, Jang HS, Noh MR, Kim J, Kong MJ, Kim JI, Park JW, Park KM. Mitochondrial NADP ${ }^{+}$-dependent isocitrate dehydrogenase deficiency exacerbates mitochondrial and cell damage after kidney ischemia-reperfusion injury. J Am Soc Nephrol. 2017;28:1200-1215.

11. Han SJ, Choi HS, Kim JI, Park JW, Park KM. IDH2 deficiency increases the liver susceptibility to ischemia-reperfusion injury via increased mitochondrial oxidative injury. Redox Biol. 2018;14:142153.

12. Kong MJ, Han SJ, Kim JI, Park JW, Park KM. Mitochondrial $\mathrm{NADP}^{+}$-dependent isocitrate dehydrogenase deficiency increases cisplatin-induced oxidative damage in the kidney tubule cells. Cell Death Dis. 2018;9:488.

13. Rodríguez-Iturbe B, Vaziri ND, Herrera-Acosta J, Johnson RJ. Oxidative stress, renal infiltration of immune cells, and salt-sensitive hypertension: all for one and one for all. Am J Physiol Renal Physiol. 2004;286:F606-F616.

14. Eddy AA. Interstitial macrophages as mediators of renal fibrosis. Exp Nephrol. 1995;3:76-79.

15. Nishida M, Hamaoka K. Macrophage phenotype and renal fibrosis in obstructive nephropathy. Nephron Exp Nephrol. 2008;110:e31e36.

16. Pan JH, Kim HS, Beane KE, Montalbano AM, Lee JH, Kim YJ, Kim JH, Kong BC, Kim S, Park JW, Shin EC, Kim JK. IDH2 deficiency aggravates fructose-induced NAFLD by modulating hepatic fatty acid metabolism and activating inflammatory signaling in female mice. Nutrients. 2018;10:679.

17. Kim S, Kim SY, Ku HJ, Jeon YH, Lee HW, Lee J, Kwon TK, Park KM, Park JW. Suppression of tumorigenesis in mitochondrial $\mathrm{NADP}(+)$-dependent isocitrate dehydrogenase knock-out mice. Biochim Biophys Acta. 2014;1842:135-143. 
18. Kim JI, Noh MR, Kim KY, Jang HS, Kim HY, Park KM. Methionine sulfoxide reductase A deficiency exacerbates progression of kidney fibrosis induced by unilateral ureteral obstruction. Free Radic Biol Med. 2015;89:201-208.

19. Shin AH, Kil IS, Yang ES, Huh TL, Yang CH, Park JW. Regulation of high glucose-induced apoptosis by mitochondrial NADP ${ }^{+}$-dependent isocitrate dehydrogenase. Biochem Biophys Res Commun. 2004;325:32-38.

20. Frezza C, Cipolat S, Scorrano L. Organelle isolation: functional mitochondria from mouse liver, muscle and cultured fibroblasts. Nat Protoc. 2007;2:287-295.

21. Noh MR, Jang HS, Song DK, Lee SR, Lipschutz JH, Park KM, Kim JI. Downregulation of exocyst Sec10 accelerates kidney tubule cell recovery through enhanced cell migration. Biochem Biophys Res Commun. 2018;496:309-315.

22. Jo SH, Son MK, Koh HJ, Lee SM, Song IH, Kim YO, Lee YS, Jeong KS, Kim WB, Park JW, Song BJ, Huh TL. Control of mitochondrial redox balance and cellular defense against oxidative damage by mitochondrial $\mathrm{NADP}^{+}$-dependent isocitrate dehydrogenase. J Biol Chem. 2001;276:16168-16176.

23. Klahr S, Morrissey J. Obstructive nephropathy and renal fibrosis. Am J Physiol Renal Physiol. 2002;283:F861-F875.

24. Yeh CH, Chiang HS, Lai TY, Chien CT. Unilateral ureteral obstruction evokes renal tubular apoptosis via the enhanced oxidative stress and endoplasmic reticulum stress in the rat. Neurourol Urodyn.
2011;30:472-479.

25. Kinter M, Wolstenholme JT, Thornhill BA, Newton EA, McCormick ML, Chevalier RL. Unilateral ureteral obstruction impairs renal antioxidant enzyme activation during sodium depletion. Kidney Int. 1999;55:1327-1334.

26. Sugiyama H, Kobayashi M, Wang DH, Sunami R, Maeshima Y, Yamasaki Y, Masuoka N, Kira S, Makino H. Telmisartan inhibits both oxidative stress and renal fibrosis after unilateral ureteral obstruction in acatalasemic mice. Nephrol Dial Transplant. 2005;20:26702680.

27. Ratliff BB, Abdulmahdi W, Pawar R, Wolin MS. Oxidant mechanisms in renal injury and disease. Antioxid Redox Signal. 2016; 25:119-146.

28. Nishida M, Fujinaka H, Matsusaka T, Price J, Kon V, Fogo AB, Davidson JM, Linton MF, Fazio S, Homma T, Yoshida H, Ichikawa I. Absence of angiotensin II type 1 receptor in bone marrow-derived cells is detrimental in the evolution of renal fibrosis. J Clin Invest. 2002;110:1859-1868.

29. Munnamalai V, Suter DM. Reactive oxygen species regulate F-actin dynamics in neuronal growth cones and neurite outgrowth. J Neurochem. 2009;108:644-661.

30. Sakai J, Li J, Subramanian KK, Mondal S, Bajrami B, Hattori H, Jia Y, Dickinson BC, Zhong J, Ye K, Chang CJ, Ho YS, Zhou J, Luo HR. Reactive oxygen species-induced actin glutathionylation controls actin dynamics in neutrophils. Immunity. 2012;37:1037-1049. 